\title{
Atmospheric patterns for heavy rain events in Calabria
}

\author{
S. Federico ${ }^{1,2}$, E. Avolio ${ }^{1,2}$, L. Pasqualoni ${ }^{2}$, and C. Bellecci ${ }^{2,3}$ \\ ${ }^{1}$ CNR-ISAC, area EX-SIR zona industriale, Lamezia Terme (CZ), Italy \\ ${ }^{2}$ CRATI Scrl, c/o Università della Calabria, Rende (CS), Italy \\ ${ }^{3}$ Facoltà di Ingegneria-Università di “Tor Vergata", via del Politecnico 1, Rome , Italy
}

Received: 7 April 2008 - Revised: 14 July 2008 - Accepted: 8 September 2008 - Published: 24 October 2008

\begin{abstract}
This study investigates the atmospheric pattern circulations associated with heavy rainfall (HR) days in Calabria, southern Italy, and contributes to the understanding of the dynamical mechanisms that produce those events.

Heavy rainfall days are extracted from the raingauge database of the "Protezione Civile Regionale", which has more than a hundred pluviometric stations for the period 1999-2007 (eight years).

To study the synoptic atmospheric circulations associated with HR we use the Regional Atmospheric Modeling System (RAMS) gridded data field of $925 \mathrm{hPa}$ and $500 \mathrm{hPa}$ geopotential height. First the number of variables is reduced by principal component analysis (PCA), then a cluster analysis (CA) is applied on those new atmospheric variables and eleven atmospheric patterns are obtained.

Clear associations emerged between each of the circulation types and rainfall patterns over Calabria for HR days. These associations can be explained by the interaction between the complex orography of the region, the sea and the synoptic scale flow.
\end{abstract}

\section{Introduction}

The Mediterranean region is characterized by torrential rainfall and flash floods at different spatial and temporal scales (Siccardi, 1996; Jansà, 1994). Several events have been studied, discussed, and reported in various countries around the Mediterranean basin (Homar et al., 2001; Fehlman et al., 2000; Buzzi and Foschini, 2000; Romero et al., 1998; Alpert et al., 2002) and heavy precipitation is the basis of the MEDEX project.

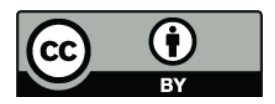

Correspondence to: S. Federico (s.federico@isac.cnr.it)
This study focuses on Calabria (Fig. 1), which ranges between $37^{\circ} 50^{\prime}$ and $40^{\circ} 05^{\prime}$ latitude north and between $15^{\circ} 30^{\prime}$ and $17^{\circ} 30^{\prime}$ longitude east. The west coast of the region is bounded by the Tyrrhenian Sea and the east and south coasts by the Ionian sea. Apennines run from north to south along the peninsula and are characterized by five main topographical features reaching 1.5-2.0 km elevations: Pollino, Catena Costiera, Sila, Serre, Aspromonte. The average width of the region is about $50 \mathrm{~km}$ in the west-east direction and $300 \mathrm{~km}$ in north-south direction. Three main valleys locate by the sea and most of agricultural and industrial sites are in those valleys.

The yearly total rainfall amount over the region is about $1000 \mathrm{~mm}$ and $83 \%$ of this amount is recorded in the cold semester from October to April (Colacino et al., 1997). Rainfall varies sizeably from west to east side and between mountains and lowlands. More precisely, the yearly average precipitation along the west coast is about $900 \mathrm{~mm}$ and it decreases to $700 \mathrm{~mm}$ along the Ionian side. The yearly total rainfall above $800 \mathrm{~m}$ elevation is usually greater than $1100 \mathrm{~mm}$ while it is less than $900 \mathrm{~mm}$ for valleys and for coastal areas. Despite this rather dry climate, precipitation is sometime torrential.

Previous studies show that intense baroclinic lee cyclones, that often develop in the Mediterranean Basin (Buzzi and Tibaldi, 1978), can be quite intense over Calabria (Federico et al., 2003a, 2006) as its peculiar geographical feature, i.e. the presence of a warm sea nearby steep mountainous ranges, determines persistent precipitation patterns over localized spots. In some cases, intense localized storms at the subsynoptic scale are the cause of major events, such as the Mediterranean Hurricane (Medicane) of 4-6 October 1996 reported by Atlas and Reale (2001), or the Crotone supercelllike storm studied by Federico et al. (2003b).

The present study is an attempt to improve the understanding of the dynamical mechanisms that produce intense precipitation over Calabria, southern Italy, from a statistical

Published by Copernicus Publications on behalf of the European Geosciences Union. 


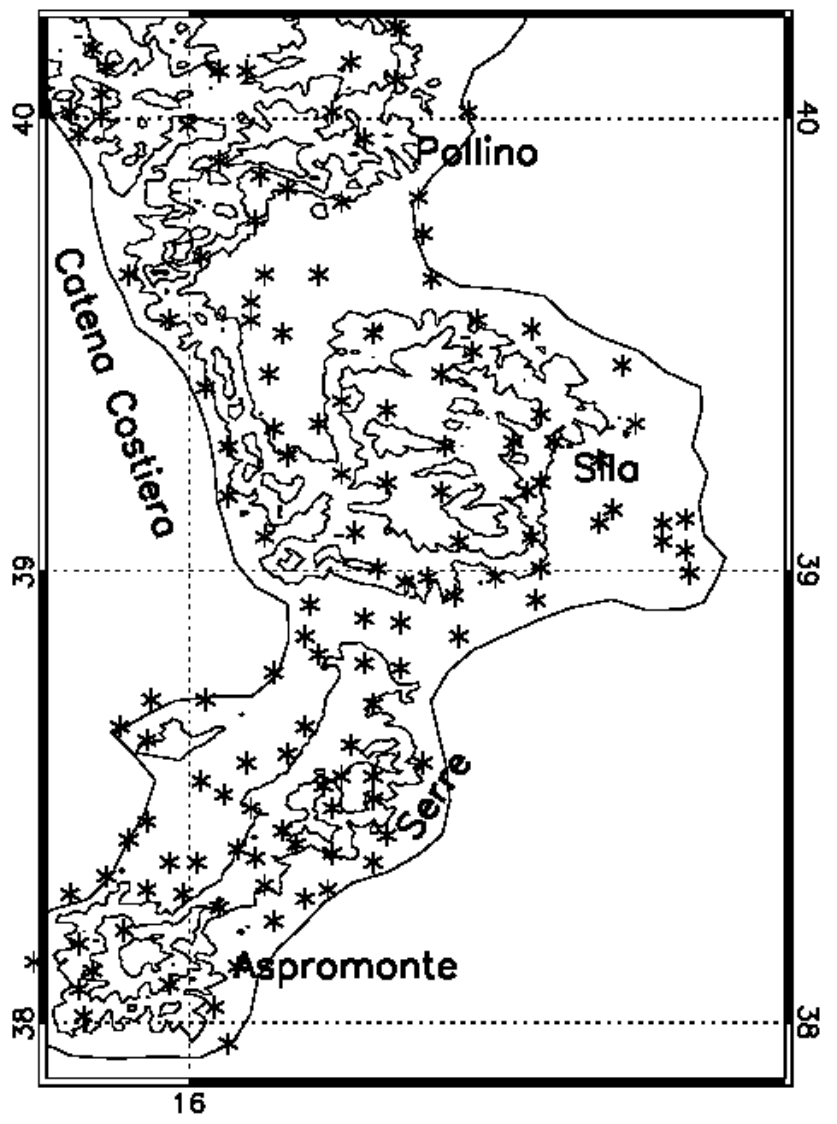

Fig. 1. Topography of Calabria peninsula with main mountain ranges names. Contours are for 500, 1000 and $1500 \mathrm{~m}$ elevation. Asterisks are rain gauge locations.

point of view. The objective is to obtain the atmospheric patterns (hereafter, AP) that produce heavy rain (HR) events and to associate them to rainfall patterns recorded over the country.

The paper is organized as follows: in Sect. 2 we introduce data and methodology, in Sect. 3 we describe the model setup, while in Sect. 4 we discuss results. Conclusions are given in Sect. 5.

\section{Data and methodology}

In this work we are interested to heavy rainfall events occurred over Calabria. For this purpose we classify an event as HR if the daily precipitation amount is greater than $60 \mathrm{~mm}$ at least in one station and greater than $20 \mathrm{~mm}$, for the same day, at least in 20 stations. The $60 \mathrm{~mm}$ threshold is chosen because it is often used in this kind of study in the Mediterranean (Lana et al., 2007; Jansà et al., 2001) and it is the threshold adopted in the MEDEX project to classify an HR event. The additional requirement that at last $20 \mathrm{~mm}$ must be recorded in 20 stations is necessary to exclude from
Table 1. Number of HR events for each season and atmospheric pattern.

\begin{tabular}{cccccc}
\hline AP & Spring & Summer & Autumn & Winter & TOTAL \\
\hline AP01 & 1 & 0 & 0 & 5 & 6 \\
AP02 & 0 & 0 & 0 & 5 & 5 \\
AP03 & 0 & 7 & 13 & 0 & 20 \\
AP04 & 1 & 0 & 1 & 2 & 4 \\
AP05 & 3 & 0 & 2 & 5 & 10 \\
AP06 & 1 & 0 & 1 & 4 & 6 \\
AP07 & 2 & 0 & 9 & 3 & 14 \\
AP08 & 3 & 0 & 3 & 6 & 12 \\
AP09 & 2 & 0 & 0 & 7 & 9 \\
AP10 & 1 & 0 & 0 & 2 & 3 \\
AP11 & 0 & 0 & 2 & 2 & 4 \\
TOTAL & 14 & 7 & 31 & 41 & 93 \\
\hline
\end{tabular}

the present analysis localized thunderstorms (Federico et al., 2003b). These thunderstorms leave more than $60 \mathrm{~mm}$ rainfall in just one or two stations and few millimetres in the nearby stations. Thus, we exclude the analysis of very localized thunderstorms.

The database is composed by the daily precipitation recorded at more than 100 raingauges (Fig. 1) from 1 January 1999 to 31 December 2007. For this period 93 HR days were found with an average of 11.6 events per year. Among the 93 HR days, 41 (44\%) are registered in winter, 31 (33\%) in autumn, $14(15 \%)$ in spring and $7(8 \%)$ in summer (Table 1). This distribution confirms the Mediterranean characteristics of the Calabrian climate (Colacino et al., 1997) and suggests that HR events are determined by the presence of a cyclone in the area that forces air masses toward the complex local orography.

In order to obtain and characterize large scale atmospheric patterns, RAMS model is run for each HR event (see also the following section). The study area extends from $0 \mathrm{E}$ to $25 \mathrm{E}$ and from $30 \mathrm{~N}$ to $50 \mathrm{~N}$, which is the target domain. This window is included in the RAMS domain (Fig. 3) and is consistent with those used in similar studies (e.g. Romero et al., 1999). The extension of the target domain and the model resolution seem consistent with the synoptic scale and meso$\alpha$ scale extension of the atmospheric patterns of HR days. Moreover a larger window was tried but association of AP and HR days was less satisfactory because features far from the Mediterranean affected the classification.

The classification of the 93 circulation patterns within the selected geographical area was obtained by Principal Component Analysis (PCA) and cluster analysis (CA). For each atmospheric field considered (geopotential height, temperature, relative humidity and winds) a data matrix is constructed with 2091 columns (grid points) and 93 rows (days) and it was subjected to PCA (S-mode) (Richman, 1986) in order to reduce the dimensions of the dataset. In the context 
of this work an S-mode analysis is preferable because it isolates subgroups of grid points with characteristic temporal variability of the under study parameter. When more than one field is considered, PCA is carried out for each field and $\mathrm{CA}$ is applied to the matrix of principal components scores. A meteorological parameter defined at different levels, e.g. temperature, gives one field for each level and PCA is carried out for each level before CA is performed.

This methodology was applied to geopotential height $(1000 \mathrm{hPa}, 925 \mathrm{hPa}$ and $500 \mathrm{hPa})$, temperature $(925 \mathrm{hPa}$ and $850 \mathrm{hPa})$, relative humidity $(925 \mathrm{hPa})$, and $925 \mathrm{hPa}$ winds ( $u$ and $v$ components). Only the most important extracted components, accounting for the $95 \%$ of the total field variance, were retained. Thus, 8 components were retained for $1000 \mathrm{hPa}$ and $925 \mathrm{hPa}$ geopotential height, 7 components were retained for $500 \mathrm{hPa}$ geopotential height, 12 components were retained for $925 \mathrm{hPa}$ and $850 \mathrm{hPa}$ temperature, 25 components were retained for $925 \mathrm{hPa}$ relative humidity and 32 components were retained for each horizontal component of the $925 \mathrm{hPa}$ wind field. The optimal classification was chosen linking the atmospheric patterns to the rainfall pattern associated, given by the average of the precipitation recorded by raingauges for the HR days belonging to each AP. The result was not sensitive to the meteorological field chosen, provided that $925 \mathrm{hPa}$ and $500 \mathrm{hPa}$ geopotential height were included into the analysis. This is not surprising because these fields already contain information about the dynamic and thermodynamic physical processes involved in HR events (Romero et al., 1999). However, the most satisfactory result was obtained considering the $925 \mathrm{hPa}$ and $500 \mathrm{hPa}$ geopotential height scores in the cluster analysis. Thus, 15 variables were used in the CA. The clustering algorithm used is the non-hierarchical $k$-means method (Anderberg, 1993). This method minimizes the sum of the intra group sum of squares $(D)$, which decreases as the number of groups $(k)$ increases. The clusters number need to be identified before the algorithms proceeds. The optimal number was selected when $D$ decrease was not significant. This distance was computed from $k=3$ to $k=20$ and shows a minimum decrease for $k=11$ (Fig. 2), which is the optimal cluster number.

\section{Model setup}

The following is a brief description of the model set up including the options selected. For details on RAMS, the reader should refer to Pielke et al. (1992) and Cotton et al. (2003).

We use one grid with $25 \mathrm{~km}$ horizontal grid spacing because we are interested to the characteristics of the flow at the synoptic and meso-a scale (Fig. 3). Thirty vertical levels, up to $17000 \mathrm{~m}$ in the terrain following coordinate system, are used in simulations. Levels are not equally spaced: layers within the Planetary Boundary Layer range between 50

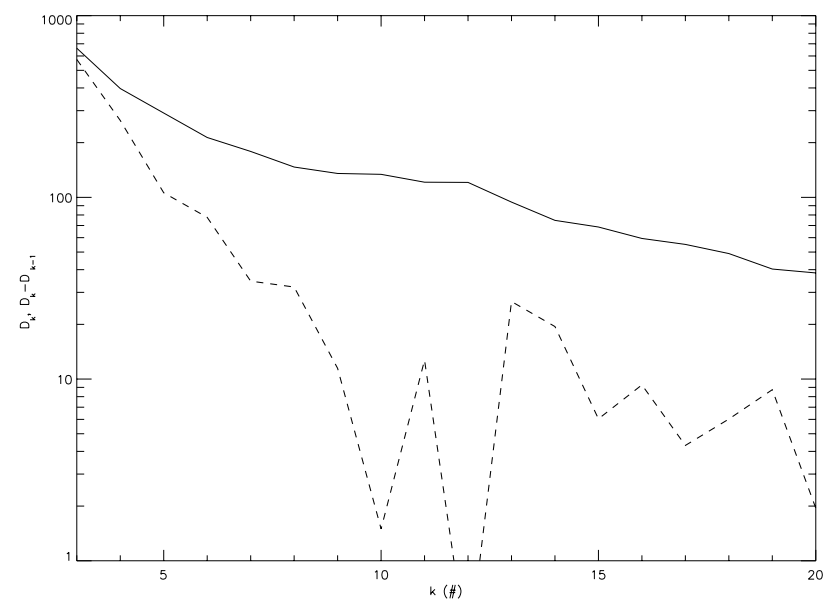

Fig. 2. Solid line: Distance $(D)$ among clusters as a function of cluster number $(k)$. Dashed line shows the distance difference $D_{k-1}-D_{k}$ for cluster number $k$.

and $200 \mathrm{~m}$ thick, whereas layers in the middle and upper troposphere are $1000 \mathrm{~m}$ thick.

Parameterization of the surface water and energy budgets and fluxes with the atmosphere are described in Walko et al. (2000). This scheme allows for subgrid patch representation inside a grid cell, and allow an explicit representation of small-scale in-homogeneity of landuse and soil physical properties.

Non-convective precipitation is computed from explicit prognostic equations for seven water categories: cloud particles, rain, pristine ice, snow, aggregates, graupel, and hail. Convective precipitation is parameterized following Molinari and Corsetti (1985) who proposed a simplified form of the Kuo scheme that accounts for updrafts and downdrafts.

Ninety-three runs are performed to simulate the synoptic scale characteristics during HR events over Calabria. Initial and dynamic boundary conditions are derived from ECMWF analysis. Each simulation starts at 12:00 UTC of the day before the HR event and lasts $36 \mathrm{~h}$. RAMS analysis at 12:00 UTC of the HR day is used to perform PCA and CA.

\section{Results}

Following the methodology described in Sect. 2, 11 APs for the HR days over Calabria were obtained. The following description is based on geopotential height $Z$ at $500 \mathrm{hPa}$ and $925 \mathrm{hPa}$, and on temperature $T$ at $850 \mathrm{hPa}$. These atmospheric patterns are shown in Fig. 3. An important point to highlight is that each AP is an average of atmospheric fields of the days belonging to each cluster. Thus, Fig. 3 does not show a real atmospheric pattern but an average of them.

To deepen further the discussion, Fig. 4 shows the precipitation field associated with each AP. In particular, its panels show the Cressman analysis (Cressman, 1959) with $0.2^{\circ}$ 
$Z(m)-500 h P a-A P \# 0106 \%$

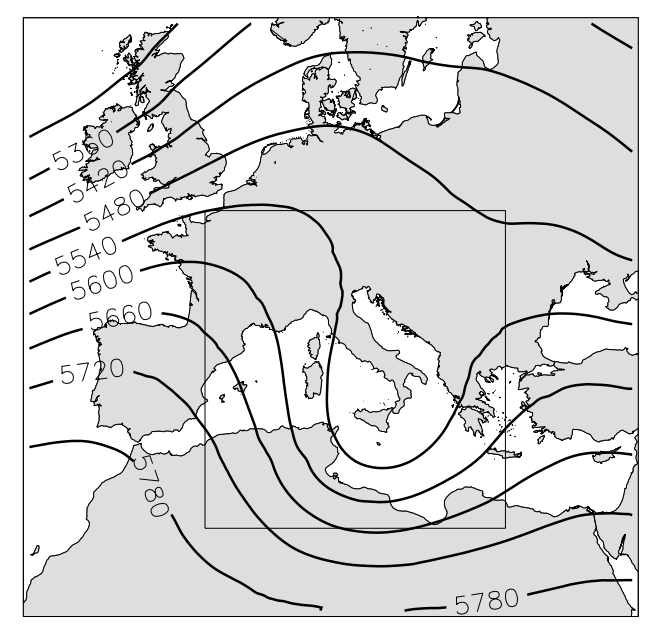

$Z(m)-500 h P a-A P \# 0205 \%$

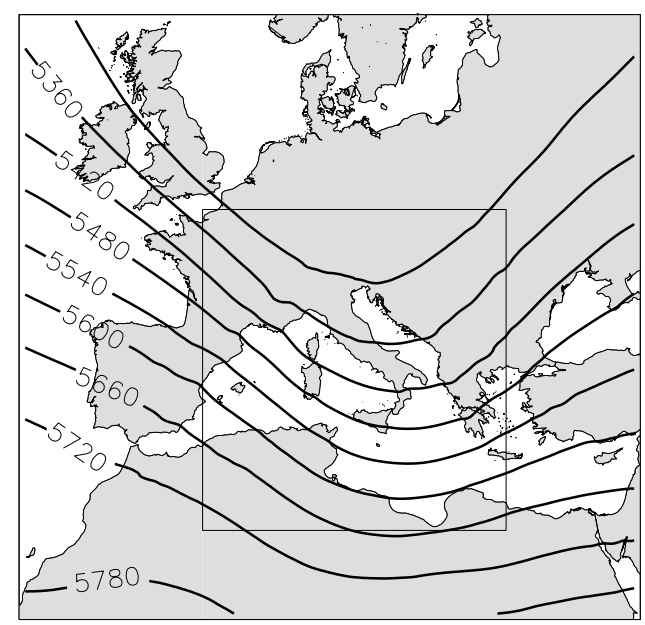

$Z(m)-T(C)-A P \# 0106 \%$

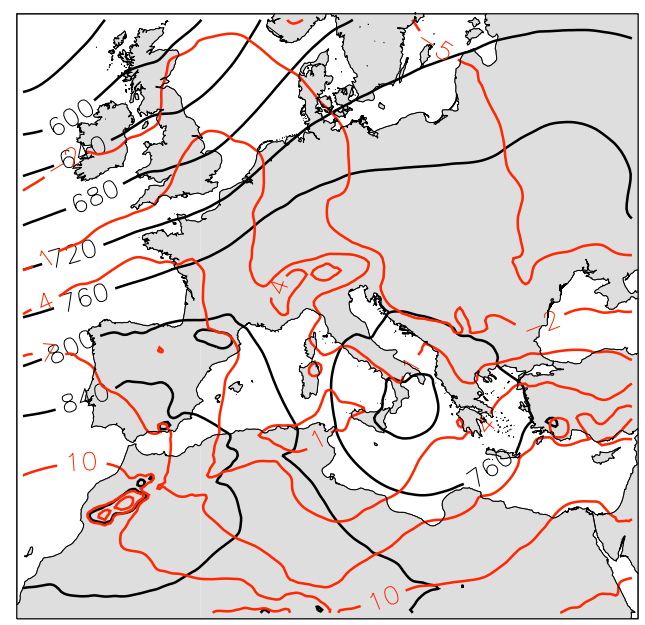

$Z(m)-T(C)-A P \# 0205 \%$

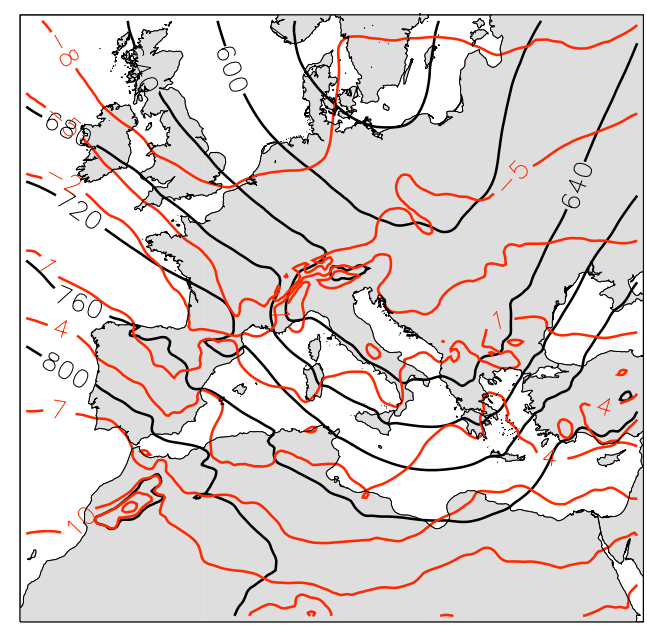

Fig. 3a. Left panel: 500hPa geopotential height (m) (contours every 40 gpm). Right panel: $925 \mathrm{hPa}$ geopotential height (solid black contours every $40 \mathrm{gpm}$ ) and $850 \mathrm{hPa}$ temperature (red contours, every $3^{\circ} \mathrm{C}$ ). The black square inside the left panels is the study domain where the classification was performed. RAMS simulations are performed for the whole domain shown in each panel. The frequency of occurrence of the patterns is shown in the upper right corner of each panel. The figure is for AP01 and AP02.

search radius of the average of all HR days belonging to each AP.

AP01 shows a geopotential low centre at $925 \mathrm{hPa}$ over the Ionian Sea and a corresponding trough at $500 \mathrm{hPa}$. AP01 accounts for two types of storms: a) cyclones that develop over the Gulf of Genoa and move from northwest to southeast; b) cyclones that originate over the Balkans and move form northeast to southwest. In both cases, the peculiar features of the storms belonging to AP01 are a $925 \mathrm{hPa}$ geopotential minimum over the Ionian Sea and a $500 \mathrm{hPa}$ cut-off low over the central Mediterranean. The average operator smears the $500 \mathrm{hPa}$ cut-off low of each storm, so that the average of these features appears as a deep trough in Fig. 3a. This pat- tern occurs mainly in winter (Table 1 ) but it is not very frequent (6\% of HR days). Precipitation associated with AP01 (Fig. 4) has a maximum over the northeast coast of the peninsula as air masses encounter the peninsula mainly from this direction.

AP02 (Fig. 3a) is characterized by a deep trough at $925 \mathrm{hPa}$ and $500 \mathrm{hPa}$ and contains most occasions when a cyclone develops on the lee of the Alps and moves from west to east over northern Italy. This baric situation over the Tyrrhenian Sea gives a rather intense thermal gradient over the Mediterranean. This pattern occurs in winter and accounts for $5 \%$ of HR days. Precipitation field (Fig. 4a) shows a maximum over northwest coast of Calabria, which 


$$
Z(m)-500 h P a-A P \# 0321 \%
$$

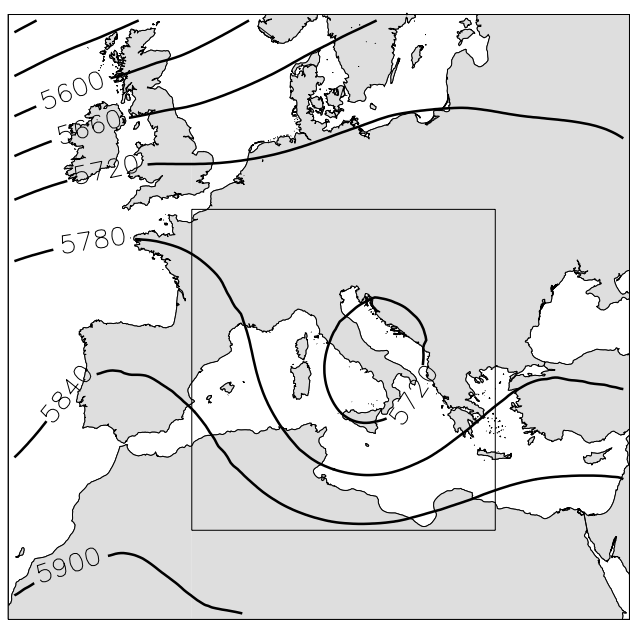

$Z(m)-500 h P a-A P \# 0404 \%$

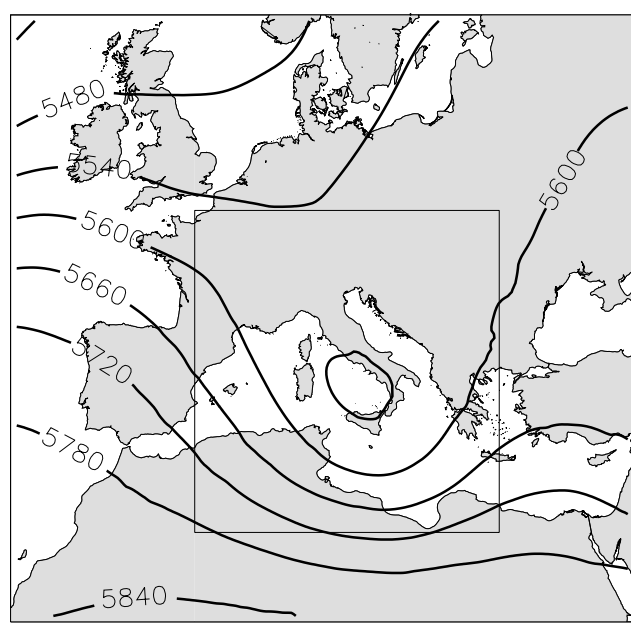

$Z(m)-T(C)-A P \# 0321 \%$

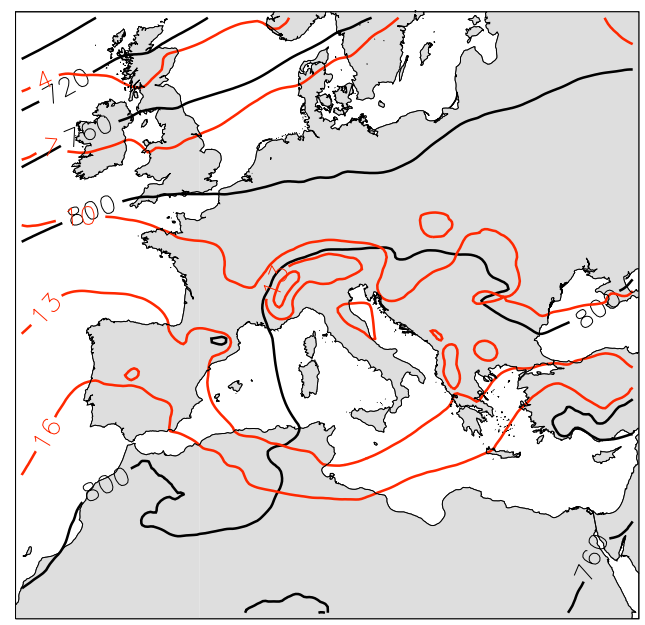

$Z(m)-T(C)-A P \# 0404 \%$

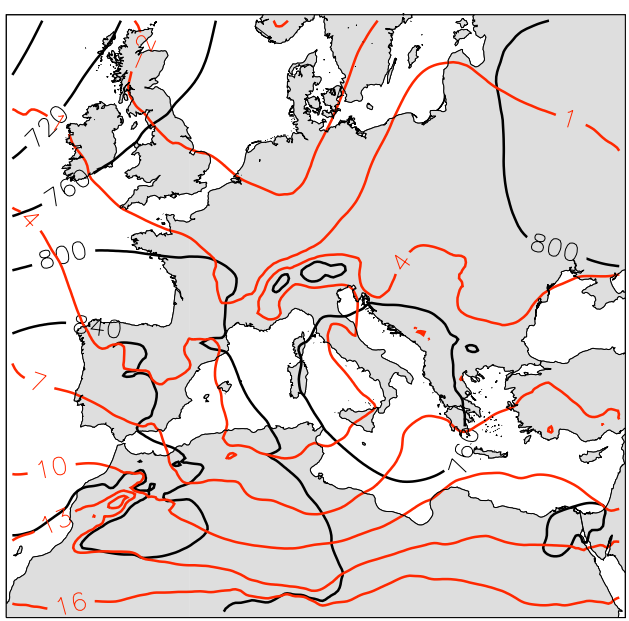

Fig. 3b. As in Fig. 3a for AP03 and AP04.

is enhanced by orographic uplift. HR pattern is a clear consequence of air masses advection toward the steep orography of Catena Costiera.

AP03 (Fig. 3b) is characterized by a cut-off low over central and southern Italy and by a rather flat field at $925 \mathrm{hPa}$. This is partially due to the average operator, which smears out the structures of each cyclone, and to the fact that in most circumstances the surface forcing is weak. For AP03, surface circulation is often characterized by advection forced by weak cyclones over the Ionian Sea and Balkans while the upper level cut-off, always present, favours the lifting of air. Because air of these storms is rather humid (see the discussion below) these conditions contribute to the great precipitation efficiency. Most of these storms develop on the lee of the Alps.
AP03 occurs in summer and autumn and accounts for $21 \%$ of HR days over Calabria. Thus this AP is the most frequent among all heavy precipitation patterns. In autumn, 8 of 13 occurrences were in September. A key factor for intense and abundant rainfall during these events is the water vapour exchange between the sea and the cyclone because the central Mediterranean Sea reaches its maximum temperature in August-September and latent heat fluxes increase with water temperature, if other conditions are the same. Humid marine air is advected toward Calabria where orographic uplift produces diabatic cooling, condensation of water vapour and precipitation. Latent heat release and humidity supply by the sea reinforce the storm and favours its persistence. AP03 rainfall pattern (Fig. 4a) shows two maxima over southeast and northeast Calabria. These maxima are tied to the air mass direction when encounter Calabrian coats. Note also that 
$\mathrm{Z}(\mathrm{m})-500 \mathrm{hPa}-\mathrm{AP} \# 0510 \%$

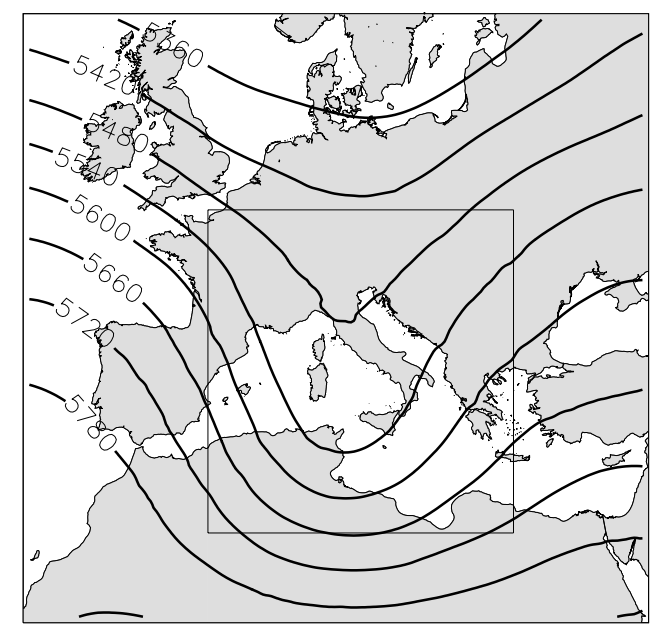

$Z(m)-500 h P a-A P \# 0606 \%$

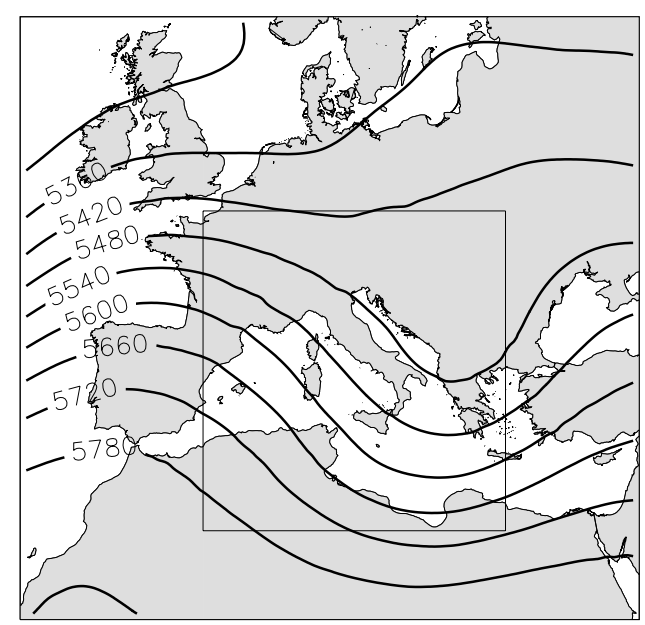

$Z(m)-T(C)-A P \# 0510 \%$

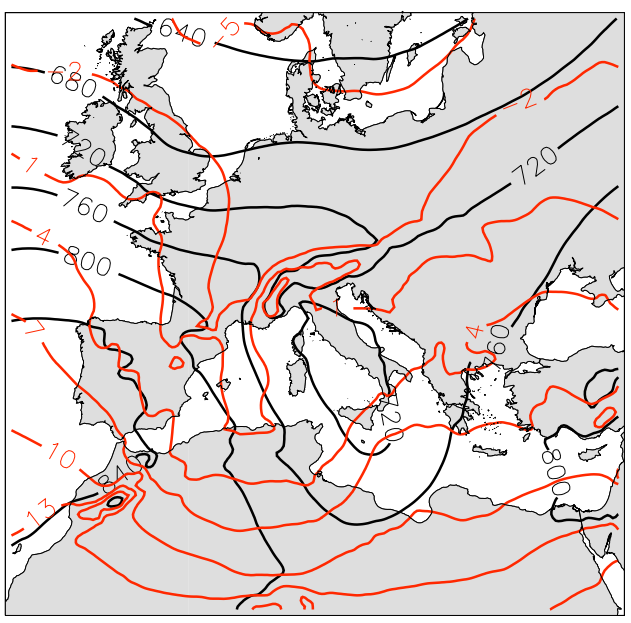

$Z(m)-T(C)-A P \# 0606 \%$

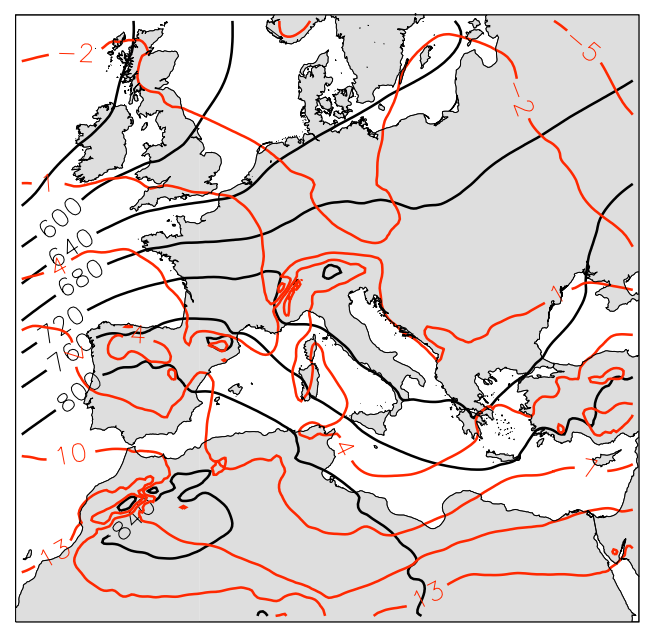

Fig. 3c. As in Fig. 3a for AP05 and AP06.

precipitation is abundant already near the coast and that the orographic uplift is less pronounced compared to other APs (e.g. AP02, AP05, AP08). The roughness change along the coastline produces convergence and upward motions, while the ambient flow is wet enough so that air masses are able to reach their Level of Free Convection and precipitation occurs (Federico et al. 2003a).

AP04 geopotential field (Fig. 3b) shows a cold cut-off low at $500 \mathrm{hPa}$ over the southern Tyrrhenian Sea and a minimum at $925 \mathrm{hPa}$ whose centre (i.e. its minimum surface pressure) is over the Ionian Sea. It accounts for cyclones that develop over the Gulf of Genoa and the Gulf of Lyon, and cross the Tyrrhenian Sea from northwest to southeast. This peculiar evolution determines a cold air pool over the Tyrrhenian Sea at $850 \mathrm{hPa}$.
AP04 can be found in winter, spring and autumn but it is not very frequent (4\% of HR days). Precipitation (Fig. 4a) affects mainly the southeast of Calabria because air masses are advected toward this side of the peninsula, as the cyclone centre moves from northwest to southeast.

AP05 (Fig. 3c) shows a geopotential low centre at $925 \mathrm{hPa}$ over the Tyrrhenian Sea and a deep trough extending from north Europe to north Africa at $500 \mathrm{hPa}$. It occurs mainly in winter but it is not uncommon in autumn and spring. It accounts for $10 \%$ of HR days. AP05 contains occasions when a cyclone develops over the Gulf of Lyon or enters the Mediterranean Basin from the Rhone valley. It accounts also for storms that develop over the Genoa Gulf. The wide minimum geopotential centre over the Tyrrhenian Sea at $925 \mathrm{hPa}$ mirrors the different trajectories that AP05 cyclones can travel, and is a consequence of the average operator. AP05 gives 

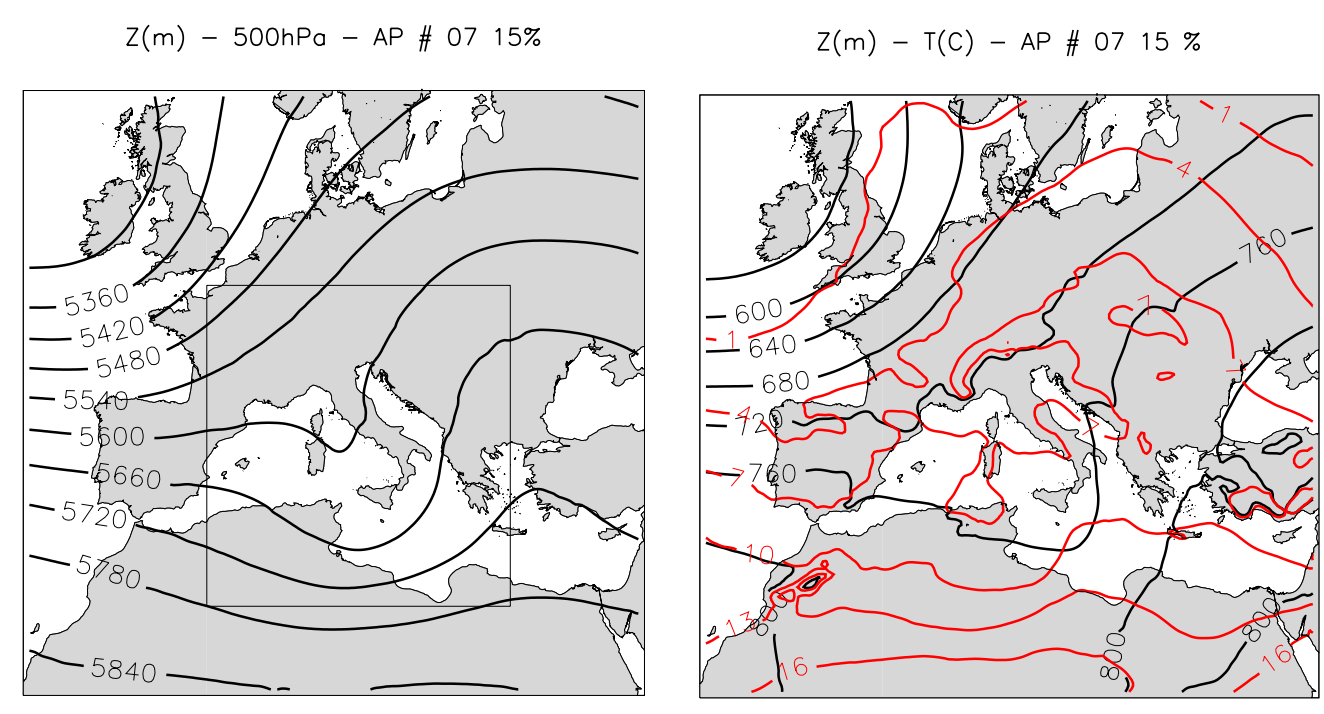

$\mathrm{Z}(\mathrm{m})-500 \mathrm{hPa}-\mathrm{AP} \# 08$ 12\%
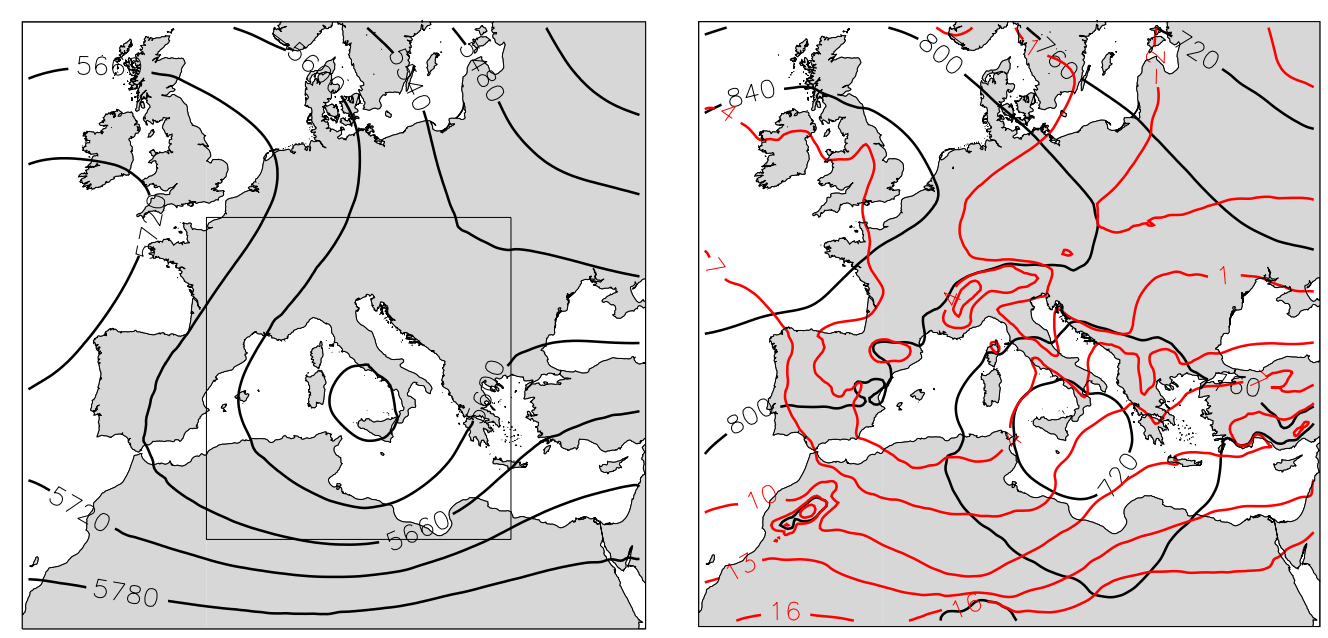

Fig. 3d. As in Fig. 3a for AP07 and AP08.

cold advection over the Tyrrhenian Sea and warm advection over the Ionian Sea. This temperature wave is rather frequent for HR days over Calabria.

Humid air masses from the Ionian Sea impinge toward Calabrian east coast where are uplifted by orography. HR pattern associated with AP05 (Fig. 4b) reflects clearly this mechanism and shows two maxima over Serre and Aspromonte. The local maximum over southeast Sila also reflects the interaction between air masses and local orography. AP05 is the third rainiest pattern over Calabria (Table 2).

AP06 (Fig. 3c) exhibits similar characteristics to AP02 with a geopotential trough at both $925 \mathrm{hPa}$ and $500 \mathrm{hPa}$. In this case, however, the trough is less pronounced and is displaced southeast of AP02. AP06 contains occasions when a cyclone develops on the lee of Alps or develops over Balkans (one occasion). It occurs mainly in winter but is possible also in spring and autumn. Its precipitation (Fig. 4b) is slightly less than AP02 and occurs on the western Calabrian coast. HR pattern is shifted to the south of AP02 precipitation field because cyclones of AP06 lie to the south of those of AP02, as evident from $500 \mathrm{hPa}$ geopotential height comparison for the two patterns.

AP07 (Fig. 3d) shows a prominent geopotential height trough at $925 \mathrm{hPa}$ and $500 \mathrm{hPa}$. It is similar to AP06 and AP02 but contains occasions when cyclones develop on the west side of the Mediterranean Basin. It occurs in autumn but it is also possible in winter and spring. This pattern is the second most frequent and accounts for $15 \%$ of heavy rainfall days. The cold air pool over Gulf of Lyon and Gulf of Genoa confirms the development of cyclones over the northwest Mediterranean. Humid air masses from the Ionian Sea are advected straight toward Calabrian east side, as shown by the 
$Z(m)-500 h P a-A P \# 0909 \%$

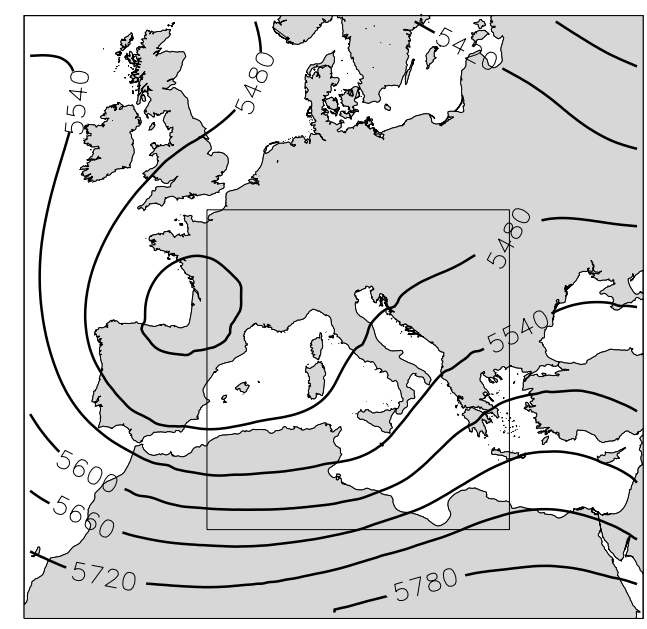

$Z(m)-500 \mathrm{hPa}-\mathrm{AP} \# 1003 \%$

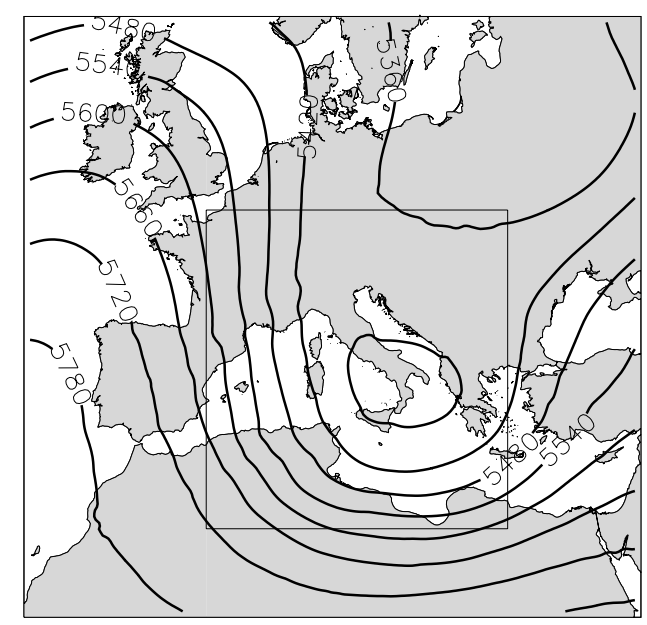

$Z(m)-T(C)-A P \# 0909 \%$

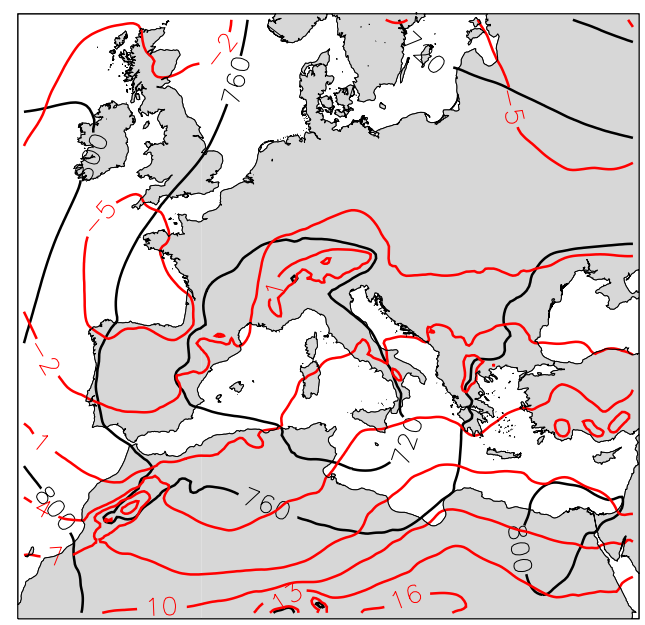

$Z(m)-T(C)-A P \# 1003 \%$

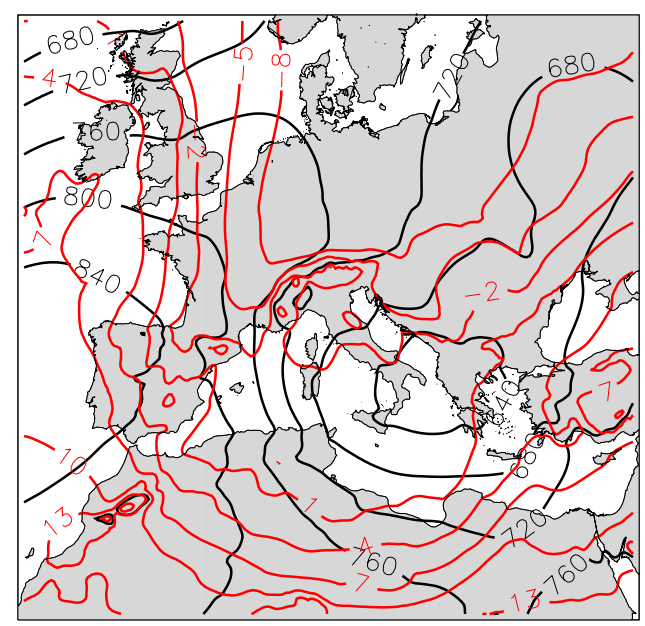

Fig. 3e. As in Fig. 3a for AP09 and AP10.

$925 \mathrm{hPa}$ geopotential field, where they are uplifted by local orography. The presence of steep mountains near a warm sea, which supplies water vapour to the overlying atmosphere, enhances precipitation very efficiently. Indeed, precipitation associated with AP07 (Fig. 4b) is the second most abundant over Calabria (Table 2). As expected from $925 \mathrm{hPa}$ geopotential field, heavy precipitation associated with this pattern affects the Calabrian east coast.

AP08 (Fig. 3d) is characterized by an upper level cut-off low and a geopotential minimum at $925 \mathrm{hPa}$. This pattern accounts for two main kinds of cyclones. The first one develops over north Africa and crosses the central Mediterranean Basin from southwest to northeast. The second type enters the Mediterranean Basin from Gibraltar strait and crosses the Mediterranean from west to east. All these storms are characterized by trajectories that cross Calabria. Following these trajectories, cyclones produce a thermal wave with cold advection over the west Mediterranean and warm advection over the Ionian Sea. This pattern is rather frequent over Calabria (13\% of HR days) and occurs in winter, spring and autumn.

Precipitation associated with AP08 (Fig. 4b) is abundant with $120 \mathrm{~mm}$ maximum average and affects the Ionian side of the peninsula. HR pattern reflects the advection of humid and warm marine air toward Calabrian Ionian coast, where the presence of steep mountains produces local maxima over Serre and Aspromonte. The shielding of Sila reduces precipitation on the northwest coast.

AP09 (Fig. 3e) shows a cut-off low at $500 \mathrm{hPa}$ over the France-Iberian border and a widespread low over the western Mediterranean Sea, which is a consequence of the smearing effect of the average operator. AP09 accounts for cyclones 

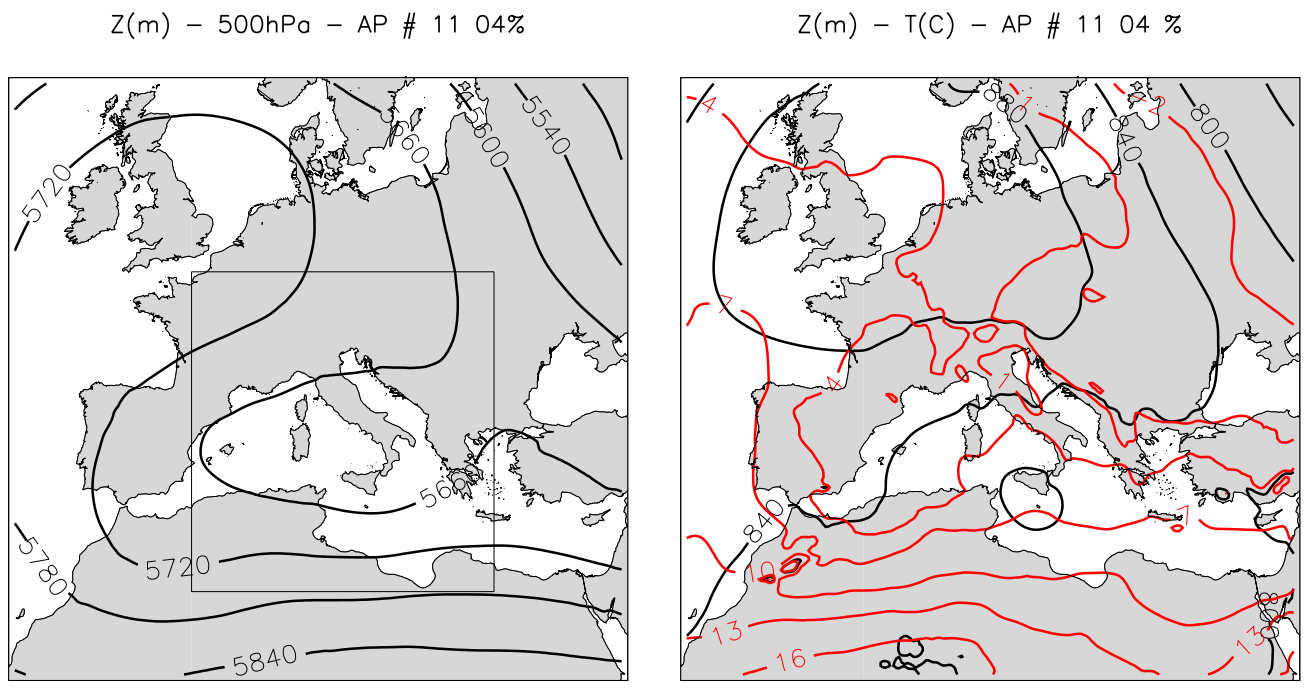

Fig. 3f. As in Fig. 3a for AP11.

Table 2. Number of HR events for different maximum rainfall thresholds (mm/day) and mean maximum rainfall $(\bar{x}$ (mm)) for each atmospheric pattern.

\begin{tabular}{ccccccc}
\hline AP & $60<x \leq 80$ & $80<x \leq 100$ & $100<x \leq 150$ & $150<x \leq 200$ & $x \geq 200$ & $\bar{x}$ \\
\hline AP01 & 4 & 0 & 1 & 1 & 0 & 100 \\
AP02 & 2 & 2 & 0 & 1 & 0 & 97 \\
AP03 & 10 & 3 & 3 & 2 & 2 & 107 \\
AP04 & 3 & 0 & 0 & 1 & 0 & 95 \\
AP05 & 4 & 1 & 2 & 2 & 1 & 124 \\
AP06 & 3 & 1 & 2 & 0 & 0 & 88 \\
AP07 & 4 & 2 & 5 & 1 & 2 & 133 \\
AP08 & 3 & 3 & 3 & 1 & 2 & 120 \\
AP09 & 3 & 2 & 1 & 2 & 1 & 121 \\
AP10 & 0 & 2 & 1 & 0 & 0 & 100 \\
AP11 & 0 & 0 & 2 & 1 & 1 & 165 \\
TOTAL & 36 & 16 & 20 & 12 & 9 & 114 \\
\hline
\end{tabular}

that develop over the western Mediterranean or enter the Basin through the Gibraltar strait. AP09 cyclones are characterized by intense pressure gradients in the central Mediterranan Basin and intense winds from south/southeast toward Calabrian Ionian coast. The consequent orographic uplift gives intense and abundant rainfall over the eastern flank of the peninsula and over main peaks.

AP09 accounts for $9 \%$ of HR days and occurs mainly in winter, even if it happened in spring in two occasions. Precipitation associated with this pattern (Fig. 4c) is abundant with a maximum average of $121 \mathrm{~mm}$. Rainfall pattern is tied to the direction of air masses advected onto the Calabrian east coast, and precipitation shows local maxima over Sila, Serre and Aspromonte. Also for this AP, orographic uplift is a fundamental mechanism to enhance precipitation while the shielding effect of mountains reduces rainfall on the west side of the peninsula.

AP10 (Fig. 3e) shows a minimum geopotential height at $925 \mathrm{hPa}$ over the Ionian Sea and Balkans and a cold cut-off low at $500 \mathrm{hPa}$. This AP contains occasions when a cyclone develops over Balkans and moves southwest affecting Calabria. These cyclones determine cold advection over Italy and can produce snowfall over Calabria, even at lowlands. AP10 is the coldest pattern in southern Italy and it is the least frequent (3\% of HR days) of all APs. Rainfall affects mainly the northeast coast of Calabria as air masses impinge onto the peninsula mainly from this direction (Fig. 4c). Again the shielding effect of Sila reduces rainfall in western Calabria.

AP11 (Fig. 3f) is similar to AP8 because contains occasions when: a) cyclones develop over north Africa and move 


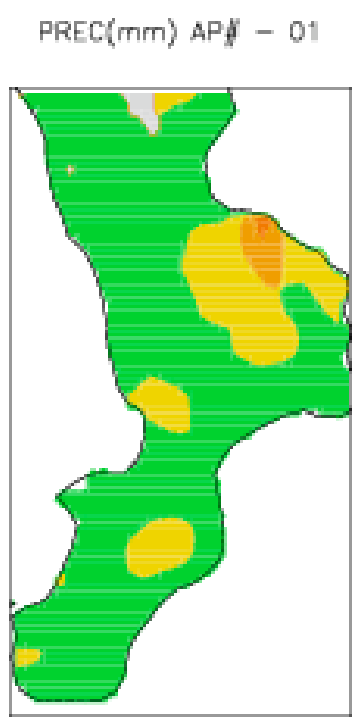

$$
\operatorname{PREC}(\mathrm{mm}) \mathrm{APH}-\mathrm{O} 2
$$

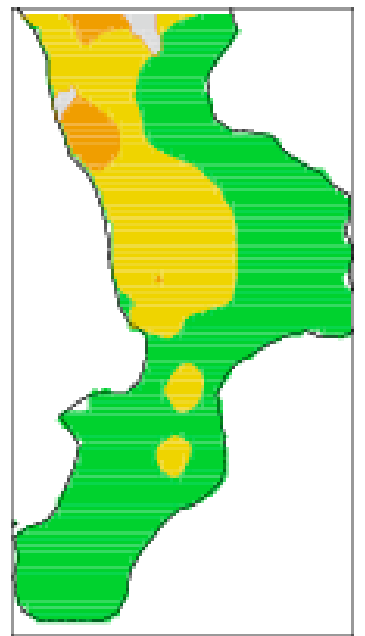

$$
\operatorname{PREC}(m m) \text { APf }-03
$$

$$
\operatorname{PREC}(\mathrm{mm}) \mathrm{APH}-04
$$
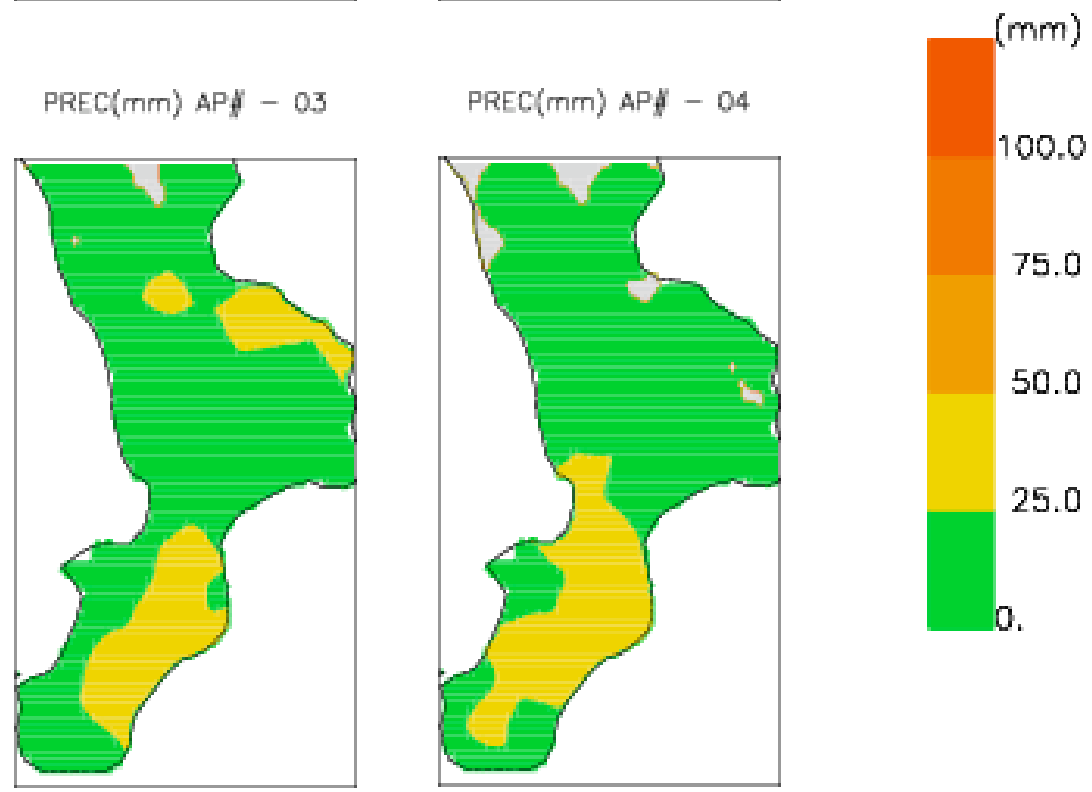

Fig. 4a. Average precipitation for days belonging to clusters 01-04 and associated with atmospheric patterns 01-04. The average precipitation, measured by the regional network (Fig. 1), was objectively assimilated by a Cressman filter with $0.2^{\circ}$ search radius. Gray areas denote missing data.

from southwest to northeast; b) cyclones enter the Mediterranean from the Gibraltar strait and cross the basin from west to east. In both cases, compared to AP08, AP11 cyclones travel more to the south, as can be inferred comparing $925 \mathrm{hPa}$ geopotential fields of the two patterns.

Despite AP11 account for $4 \%$ of HR days, it is important because represents the most rainy AP. Precipitation associated with this pattern affects mainly the Ionian side of the peninsula. There are two main precipitation spells in northeast and southeast Calabria, which reflect the direction of air masses that impinge onto Calabrian coasts. In particular the northernmost maximum is associated with AP cyclones that transit more to the south because in this situation air masses are advected toward Calabrian east coast from northeast.

It is interesting to compare the eleven precipitation patterns obtained for years 1999-2007 with the average distribution of annual rainfall over Calabria for the same years (Fig. 5). This distribution has several local maxima over main peaks that clearly show the role of the orographic uplift. Moreover there is a precipitation decrease going from Tyrrhenian to Ionian side. If we exclude AP02 (6\% of HR days) and AP06 (5\% of HR days), which have more rain on the west side of the peninsula, all other APs show more rain on the Ionian side. Thus, Mediterranean cyclones usually 

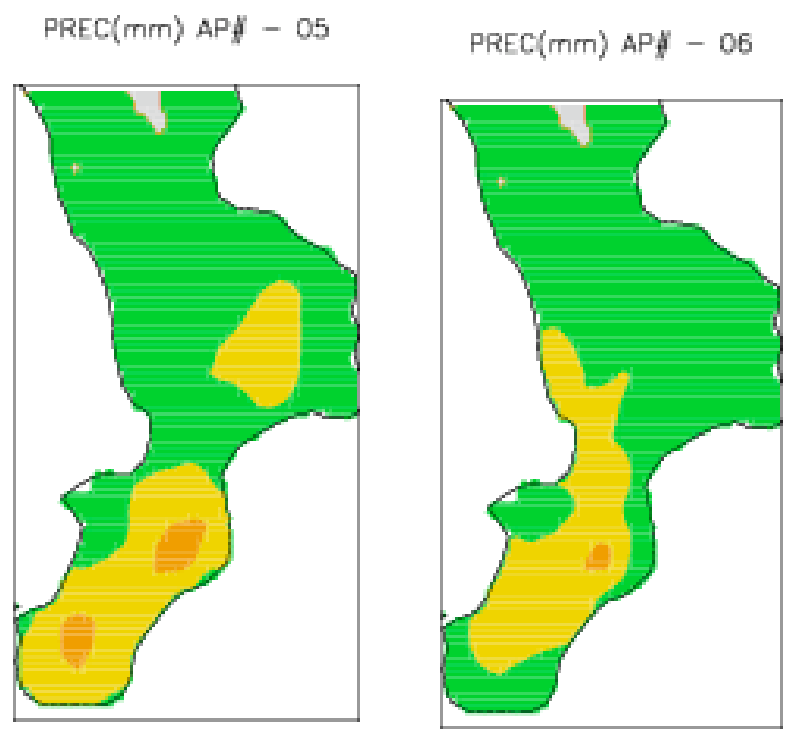

$$
\operatorname{PREC}(\mathrm{mm}) \text { APH }-07
$$

$$
\operatorname{PREC}(m m) A P H-O B
$$
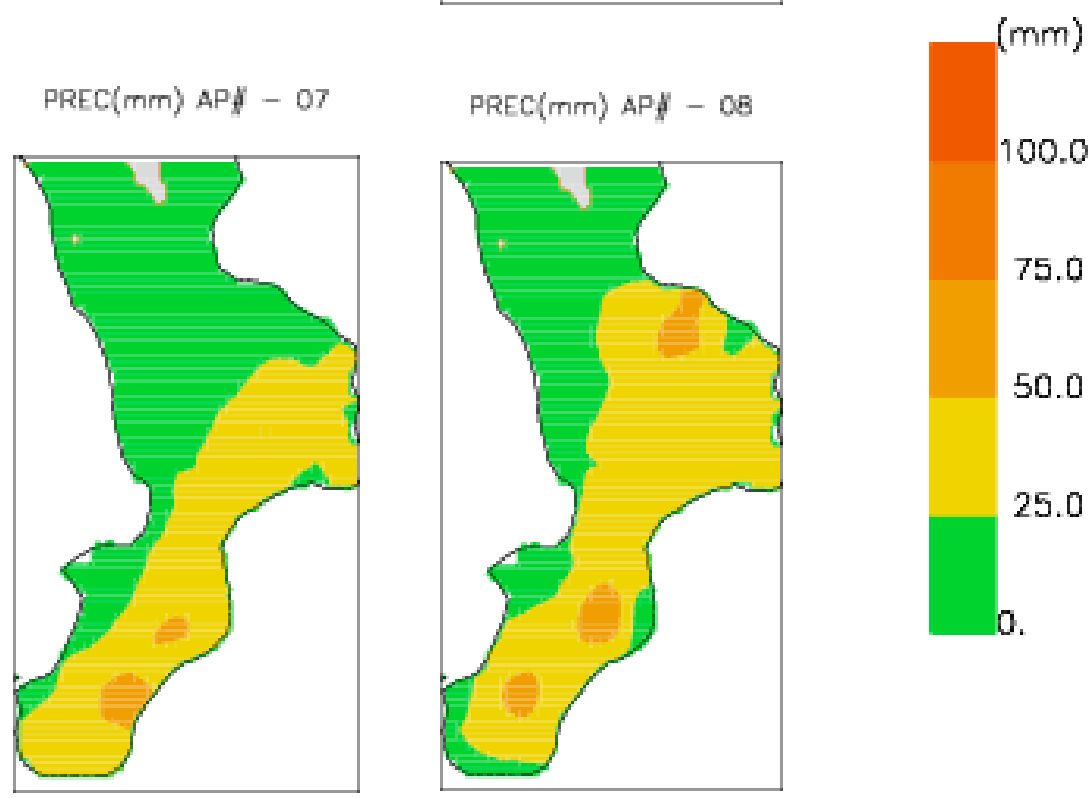

Fig. 4b. As in Fig. 4a for atmospheric patterns 05-08.

impact Calabria from west to east leaving more rain on the west side, nevertheless the heaviest rainfall events occur on the east side of the country. This result is important for the Regional Civil Protection Agency, which is mainly interested to heavy precipitation events, for best positioning of specific instrumentation, as meteorological radars and wind profilers, and for the logistic layout of means for crisis management.

\section{Conclusions}

Eleven atmospheric patterns have been obtained to explain heavy rain events in Calabria. This has been done performing a cluster analysis of 93 heavy rainfall days occurred from 1999 to 2007, based on principal component analysis of geopotential fields at $925 \mathrm{hPa}$ and $500 \mathrm{hPa}$. Despite patterns do not represent real atmospheric field because they are averages of real fields, most of them are characterized by the presence of synoptic and sub-synoptic scale cyclones, which develop in the Mediterranean and have a major impact on Calabrian rainfall. A clear and useful association between the circulation patterns and the rainfall pattern has been established.

Heavy precipitation storms over Calabria can be classified in four main groups: a) storms that originate on the lee of the Alps (including those over the Gulf of Genoa); b) storms that develop in the western Mediterranean (Gulf of Lyon, Rhone 

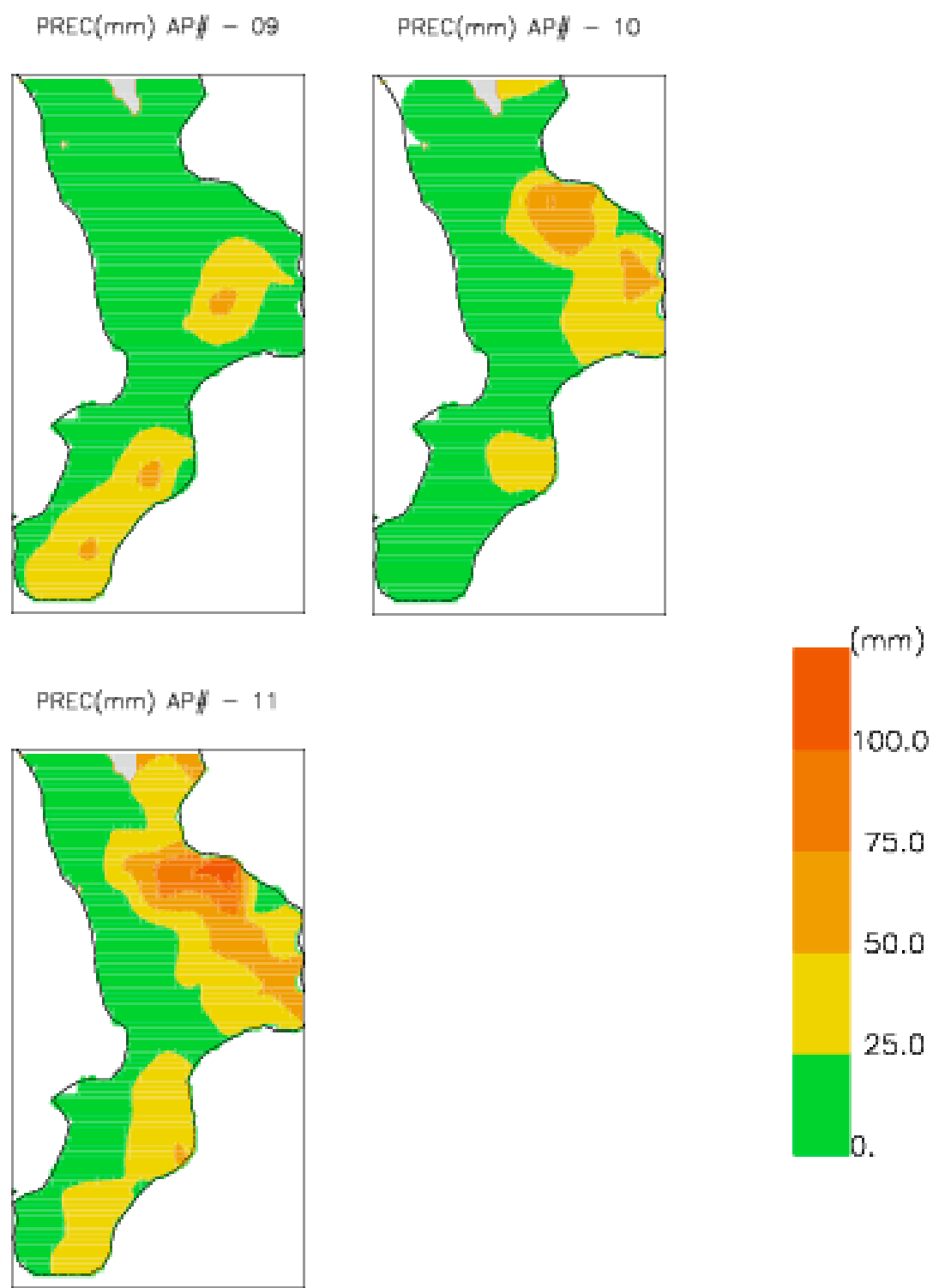

Fig. 4c. As in Fig. 4a for atmospheric patterns 09-11.

valley, Iberia); c) storms that develop in northern Africa or enter the Mediterranean from the Gibraltar strait; d) storms that move over the central Mediterranean from Balkans and eastern Europe.

Storms of class a) are the most frequent and belong to all AP from AP01 to AP06. They affect both the Tyrrhenian and Ionian side of the peninsula. In particular when a cyclone travels mainly from west to east (AP02, AP06) over northern Italy precipitation occurs on the west side of the peninsula. When cyclones travel mainly from north to south (AP01, AP03, AP04, AP05) precipitation occurs on the east side of Calabria.
Storms of class b) are included in patterns AP04, AP05, AP07 and AP09. These cyclones advect air masses from south-southeast toward Calabrian Ionian side and orographic uplift plays a key role. Thus, precipitation maxima occur on the upwind side of mountains and over main peaks, while orographic shielding reduces rainfall on the west side of Calabria.

Storms of class c) are included in AP07, AP08, AP09 and AP11. Also for this class rainfall affects the Ionian side of Calabria and orography plays a key role. The water vapour exchange between the sea and overlaying air masses, which travel a long fetch over the Ionian Sea, is another important physical factor of these storms. 

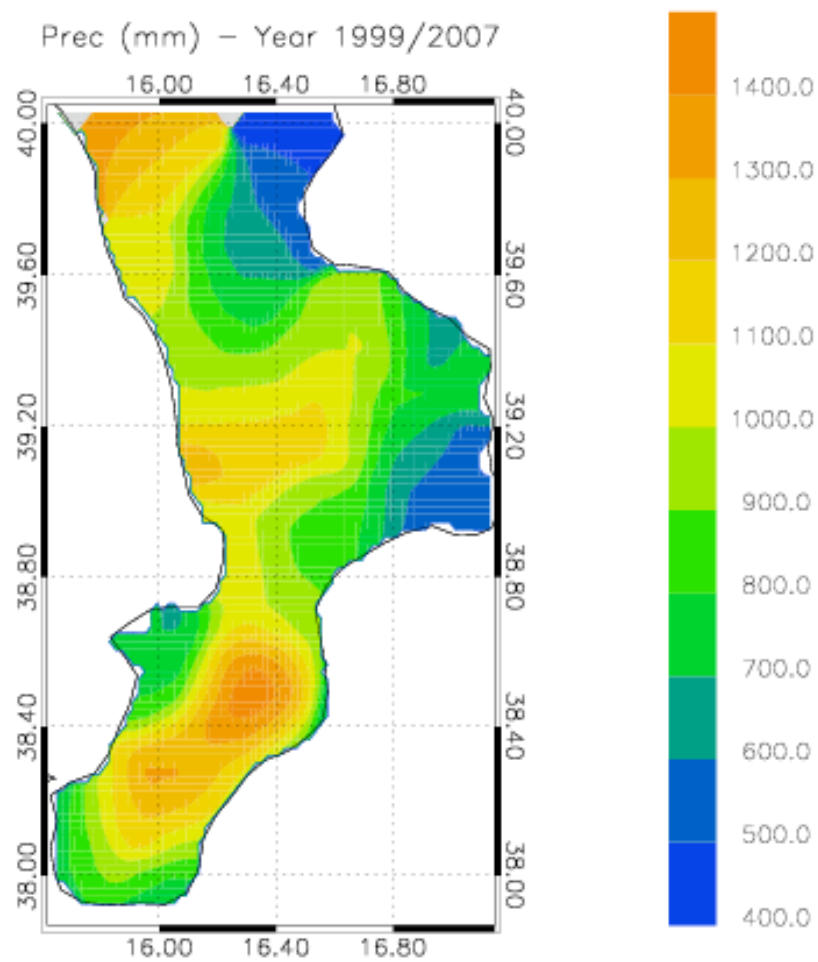

Fig. 5. Yearly average precipitation for years 1999-2007.

Storms of class d) belong to AP01, AP06 and AP10. These cyclones give intense and abundant rainfall and, even if not shown in this paper, are often accompanied by strong winds. Convective instability is generated by advection of cold air masses over the warm sea. In particular AP10 accounts for the coldest intrusion of air masses from Balkans, which can produce snowfall at lowlands.

AP03 deserves special mention. This atmospheric pattern occurs basically in summer and early autumn when the sea surface temperature is high. Storms of AP03 do not exhibit a deep cyclone at the surface but they have a clear cold cutoff low at $500 \mathrm{hPa}$. This baric situation favours vertical motion of air masses, which develops in a rather humid ambient due to the water vapour supply from the Mediterranean Sea. These conditions contribute to the great precipitation efficiency. Moreover AP03 is the most frequent heavy precipitation pattern over Calabria.

The results obtained in this paper should be valuable not only in the context of synoptic scale numerical weather prediction and as a complement for meso-scale models, but also to plan actions to manage heavy precipitation storms. In particular Regional Civil Protection Agency can use the results of this work for the best displacement of specific instrumentation and means. An important result obtained for this issue is that despite the yearly average rainfall is greater on the west side of the region, heaviest rain occurs mainly on the east side of Calabria.
Acknowledgements. This work was partially realized in the framework of the project MICENA. We are grateful to "Protezione Civile della Calabria" for raingauge data and to "Aeronautica Militare" and ECMWF for MARS access.

Edited by: A. Mugnai and V. Kotroni

Reviewed by: S. Michaelides and two other anonymous referees

\section{References}

Alpert P., Ben-Gai, T., Baharad, A., and co-authors: The paradoxial increase of Mediterranean extreme daily rainfall in spite of decrease in total values, Geophys. Res. Lett., 29, 1536, doi:10.1029/2001GL013554, 2002.

Anderberg, M. R.: Cluster Analysis for Applications, Academic Press, New. York, 359 pp., 1993.

Atlas, R. and Reale, O.: Tropical cyclone-like vortices in the extratropics: Observational evidence and synoptic analysis, Weather Forecast., 16, 7-34, 2001.

Buzzi, A. and Tibaldi, S.: Cyclogenesis on the lee of the Alps: A case study, Q. J. Roy. Meteor. Soc., 104, 271-287, 1978.

Buzzi, A. and Foschini, L.: Mesoscale meteorological features associated with heavy precipitation in the southern Alpine region, Meteorol. Atmos. Phys., 72, 131-146, 2000.

Colacino, M., Conte, M., and Piervitali, E.: Elementi di climatologia del la Calabria, IFA-CNR, 218 pp., 1997.

Cotton, W. R., Pielke Sr., R. A., Walko, R. L., Liston, G. E., Tremback, C. J., Jiang, H., McAnelly, R. L., Harrington, J. Y., Nicholls, M. E., Carrio, G. G., and McFadden, J. P.: RAMS 2001: Current satus and future directions, Meteor. Atmos., 82, 5-29, 2003.

Cressman, G. P.: An operational objective analysis system, Mon. Weather Rev., 87, 367-374, 1959.

Federico, S., Bellecci, C., and Colacino, M.: Quantitative precipitation of the Soverato flood: the role of orography and surface fluxes, Nuov. Cim. C, 26C, 7-22, 2003a.

Federico, S., Bellecci, C., and Colacino, M.: Numerical simulation of Crotone flood: storm evolution, Nuov. Cim. C, 26C, 357-371, 2003b.

Federico, S., Avolio, E., Bellecci, C., Colacino, M.: The application of LEPS technique for Quantitative Precipitation Forecast (QPF) in Southern Italy, Adv. Geosci., 7, 1-8, 2006, http://www.adv-geosci.net/7/1/2006/.

Fehlmann, R., Quadri, C., and Davies, H. C.: An Alpine rainstorm: Sensitivity to the mesoscale upper level structure, Weather Forecast., 15, 4-28, 2000.

Homar, V., Ramis, C., and Alonso, S.: A deep cyclone of African origin over the Western Mediterranean: diagnosis and numerical simulation, Ann. Geophys., 20, 93-106, 2001, http://www.ann-geophys.net/20/93/2001/.

Jansà, A., Radinovic, D., Alpert, P., Genovés, A., Campins, J., and Picornell, M. A.: Mediterranean cyclones, Subject of a WMO Project, Internat. Symposium on the Life Cycle of Extratropical Cyclones, Bergen, Vol. II, 26-31, 1994.

Jansà, A., Genovés, A., Picornell, M. A., Campins, J., Riosalido, R., and Carretero, O.: Western Mediterranean cyclones and heavy rain. Part II: Statistical approach, Meteorol. Appl., 8, 43-56, 2001. 
Lana, A., Campins, J., Genovés, A., and Jansà, A.: Atmospheric patterns for heavy rain events in the Balearic Islands, Adv. Geosci., 12, 27-32, 2007,

http://www.adv-geosci.net/12/27/2007/.

Molinari, J. and Corsetti, T.: Incorporation of cloud-scale and mesoscale down-drafts into a cumulus parametrization: results of one and three-dimensional integrations, Mon. Weather Rev., 113, 485-501, 1985.

Pielke, R. A., Cotton, W. R., Walko, R. L., Tremback, C. J., Lyons, W. A., Grasso, L. D., Nicholls, M. E., Murran, M. D., Wesley, D. A., Lee, T. H., and Copeland, J. H.: A comprehensive meteorological modelling system-RAMS, Meteorol. Atmos. Phys., 49, 69-91, 1992.

Romero, R., Ramis, C., Alonso, S., Doswell III, C. A., and Stensrud, D. J.: Mesoscale Model Simulations of Three Heavy Precipitation Events in the Western Mediterranean Region, Mon. Weather Rev., 126, 1859-1881, 1998.
Romero, R., Sumner, G., Ramis, C., Genovés, A.: A classification of the atmospheric circulation patterns producing significant daily rainfall in the Spanish Mediterranean are, Int. J. Climatol., 19, 765-785, 1999.

Siccardi, F.: Rainstorm hazards and related disasters in the western Mediterranean region, Remote Sens. Rev., 14, 5-21, 1996.

Walko, R. L., Band, L. E., Baron, J., Kittel, T. G., Lammers, R., Lee, T. J., Ojima, D., Pielke Sr., R. A., Taylor, C., Tague, C., Tremback, C. J., and Vidale, P. L.: Coupled Atmosphere-BiosphereHydrology Models for environmental prediction, J. Appl. Met., 39, 931-944, 2000. 